\title{
Copper oxide derived from copper(I) complex of 2-acetylpyridine-N(4)- (methoxy phenyl)thiosemicarbazone as an efficient catalyst in the reduction of 4-nitrophenol
}

\author{
Omar Abdullahi Wafudu Handy, Mohamad Shazwan Shah Jamil, Mustaffa Shamsuddin \\ Department of Chemistry, Faculty of Science, Universiti Teknologi Malaysia, 81310 UTM Johor Bahru, Johor, Malaysia \\ *Corresponding author: shazwan.shah@utm.my
}

\section{Article history}

Received 5 December 2019

Revised 10 Mac 2020

Accepted 9 April 2020

Published Online 15 June 2020

Graphical abstract

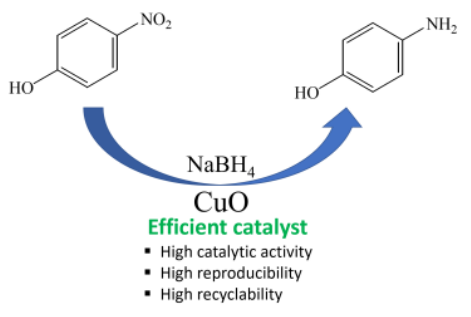

\begin{abstract}
A copper(I) complex of 2-acetylpyridine-N(4)-(methoxy phenyl)thiosemicarbazone was successfully synthesized and structurally characterized using Fourier transform infrared (FTIR), Ultraviolet-visible (UV-Vis) and nuclear magnetic resonance (NMR) spectroscopies, thermal gravimetric analysis (TGA) and $\mathrm{CHN}$ elemental analyses. The complex was converted into copper oxide in a simple, efficient, and cheap method via solid state thermal decomposition. Test of the catalytic performance of the copper(I) complex and copper oxide were in the reduction of 4-nitrophenol (4-NP) to 4-aminophenol (4-AP) shows that copper oxide has a higher catalytic activity $(98.7 \%)$ compared to the copper(l) complex $(78.2 \%)$. Optimization of the catalyst loading revealed that $1.0 \mathrm{~mol} \%$ of catalyst was the most optimized amount with the highest conversion (98.7\%) than any other amounts, $0.5 \mathrm{~mol} \%(96.8 \%), 1.5 \mathrm{~mol} \%$ $(95.4 \%)$ and 2.0 mol\% (89.6\%). Recyclability and reproducibility tests of copper oxide prove that this catalyst was very efficient, exhibit excellent reproducibility with consistent catalytic performances and could be reused four times without significant decrease in the catalytic activities.
\end{abstract}

Keywords: Copper oxide, copper(I) complex, thiosemicarbazones, 4-nitrophenol reduction

\section{INTRODUCTION}

Copper oxide $(\mathrm{CuO})$ is an important transition metal oxide with many practical applications such as catalysis, gas sensors, solar cells, battery materials and antimicrobial in biomedical studies [1, 2, 3, 4]. Due to its numerous applications, the synthesis of nanostructured $\mathrm{CuO}$ has also attracted considerable attention. Various synthetic methods have been reported for the preparation of $\mathrm{CuO}$ nanoparticles including electrochemical, hydrothermal, solvothermal, sonochemical, mechanochemical and biological methods $[5,6,7,8,9]$. Although these preparation methods are already established, however there are some disadvantages associated with these techniques. The electrochemical and chemical processes are quite expensive, involving some sophisticated equipment and require harsh conditions and the use of toxic chemicals. Biological approach on the other hand is cheaper, safer and environmental-friendly, however the process takes much longer time as the initial stage involves the extraction of biological resources [10]. Amongst all these techniques, the solid-state thermal decomposition of transition metal complexes as precursor is one of the simplest technique for preparing nanosized transition-metal oxides [11]. By selecting an appropriate precursor together with a rational calcinations procedure, products with nano sizes could be obtained. This method also has potential advantages, including high yield of pure products, absence of solvent, and exempting the need for special equipment.

In this paper, we describe the synthesis and characterisation of copper oxide from the thermal decomposition of copper(I) complex of 2-acetylpyridine-N(4)-(methoxy phenyl)thiosemicarbazone as novel precursor. The catalytic activity of the synthesized $\mathrm{CuO}$ was evaluated towards the reduction of 4-nitrophenol in the presence of sodium borohydride as a reducing agent.

\section{EXPERIMENTAL}

\section{Materials and methods}

All the chemicals and reagents used in this study were commercially purchased and used, as received without further purification. Solvents were distilled before use and dried over molecular sieves $(4 \AA \hat{)})$. All glassware were washed and dried overnight in an oven. The reactions were conducted under an inert atmosphere of nitrogen. The products obtained were collected using vacuum filtration and dried over silica gel in a desiccator before characterization. The synthesized products were characterized by melting point, UV-Vis, FTIR and ${ }^{1} \mathrm{H}$ NMR spectroscopies. The UV-Vis spectra were recorded in dimethylformamide (DMF)/chloroform $\left(\mathrm{CHCl}_{3}\right)$ solutions using a Shimadzu model UV-Vis probe 1800 spectrophotometer in the range of $200-800 \mathrm{~nm}$. The infrared spectra were obtained using the FTIR Frontier-Elmer 1800 Model spectrophotometer in the range of 4000$400 \mathrm{~cm}^{-1}$. Solution state ${ }^{\mathrm{I}} \mathrm{H}-\mathrm{NMR}$ for the ligands and the complexes were recorded on a Bruker Avance $400 \mathrm{MHz}$ spectrometer analyzer using deuterated chloroform $\left(\mathrm{CDCl}_{3}\right)$ and deuterated acetone $\mathrm{d}_{6}$ as a solvent. Chemical shifts were verified, as $\delta$ values in part per million (ppm) relative to tetra-methyl silane (TMS) as the internal reference standard. Melting points were determined using Electro-thermal 1900 Model. The elemental analysis of carbon, hydrogen, nitrogen and sulphur, was elucidated according to the ligands and complexes 
molecular weight. The thermographic analysis (TGA) was recorded on a Mettler Toledo TGA/SDTA851E instrument and X-Ray diffraction (XRD) patterns were recorded using a Bruker D8 Advance powder diffractometer with a $\mathrm{Cu} \mathrm{K \alpha}$ radiation $(\lambda=1.54060 \AA)$ operating at 40 $\mathrm{kV}$ and $30 \mathrm{~mA}$ in the $2 \theta$ range from $10^{\circ}$ to $90^{\circ}$.

\section{Preparation of thiosemicarbazide}

N(4)-(methoxyphenyl)thiosemicarbazide was prepared by mixing $\mathrm{N}(4)$-(Methoxy-phenyl)isothiocyanate $(3 \mathrm{~mL}, 3.54 \mathrm{~g}, 21.46 \mathrm{mmol})$ with hydrazine monohydrate $(5 \mathrm{~mL}, 5.15 \mathrm{~g}, 100 \mathrm{mmol})$. The reaction mixture was stirred at room temperature for 2 hours. A white precipitate formed was collected via vacuum filtration, washed with cold diethyl ether, and dried in a desiccator over silica gel. The silky white product was recrystallized from methanol. Yield $83.9 \%$. Melting point: $152-$ $153^{\circ} \mathrm{C}$. This value is consistent with the previous reported data [12].

\section{Synthesis of thiosemicarbazone ligand}

$\mathrm{N}(4)$-(methoxyphenyl)-thiosemicarbazide $(0.3624 \mathrm{~g}, 2 \mathrm{mmol})$ in ethanol $(15 \mathrm{~mL})$ was mixed with 2-acetylpyridine $(0.24 \mathrm{~mL}, 0.242 \mathrm{~g}, 2$ $\mathrm{mmol})$ in a round bottom flask. Acetic acid $(0.2 \mathrm{~mL})$ was added to the mixture and refluxed in nitrogen flow for 4 hours. A yellowish-orange product formed was filtered and washed with ethanol. Then, the product was washed with diethyl ether and dried over silica gel in a desiccator. Yield, $0.2401 \mathrm{~g}, 87.0 \%$. Colour: Yellowish-orange. Melting point: 173 $174^{\circ} \mathrm{C}$. This value is consistent with the previous reported data [12].

\section{Preparation of tris-(triphenylphosphine)copper(I) nitrate}

In a $25 \mathrm{~mL}$ beaker, copper(I) nitrate trihydrate $(0.365 \mathrm{~g}, 1.5 \mathrm{mmol})$ was dissolved in ethanol $(10 \mathrm{~mL})$. In another beaker, triphenylphosphine $(1.965 \mathrm{~g} ; 7.5 \mathrm{mmol})$ was also dissolved in ethanol $(30 \mathrm{~mL})$ and warmed. The two solutions were mixed in a $100 \mathrm{~mL}$ round bottom flask and refluxed for 1 hour. The resulting mixture was allowed to cool to room temperature. The white product was filtered, washed with cold ethanol and followed by diethyl ether, then dried in a desiccator over silica gel. Yield $0.7796 \mathrm{~g}, 85.4 \%$. Melting point: $154-$ $156^{\circ} \mathrm{C}$. This value is in good agreement with the published data [13].

\section{Synthesis of 2-acetylpyridine-N(4)-(methoxyphenyl) thiosemicarbazone-tris-(triphenyl-phosphine)copper(I) nitrate}

Tris-(triphenylphosphine)copper(I) nitrate $(0.912 \mathrm{~g}, 1 \mathrm{mmol})$ was dissolved in dichloromethane $(10 \mathrm{~mL})$ and stirred for 30 minutes under nitrogen flow at room temperature. To the solution, a solution of 2acetylpyridine-N(4)-(methyl phenyl)thiosemicarbazone $(0.181 \mathrm{~g}$, $1 \mathrm{mmol})$ dissolved in dichloromethane $(10 \mathrm{~mL})$ was added. The resulting mixture turned to reddish colour and was stirred at room temperature for 3 hours. Then, the solution reduced to a small volume under vacuum. Brown coloured complex was developed by diffusion of diethyl ether into the filtrate. Yield: $78 \%$ Colour: Brown crystals, melting point $259-260^{\circ} \mathrm{C}$. Anal Calcd for $\mathrm{CuC}_{6}{ }_{6} \mathrm{H}_{61} \mathrm{~N}_{5} \mathrm{P}_{3} \mathrm{O}_{3} \mathrm{~S}$ (1192.807 g/mol: Calcd: C, 69.01, H, 5.20, N, 5.21, S, $2.67 \%$ ) Found: C, 69.14, H, 5.15, N, 5.87, S, $2.69 \%$.

\section{Thermal decomposition of 2-acetylpyridine-N(4)- thiosemicarbazone of copper(I) nitrate to copper oxide}

$0.5 \mathrm{~g}$ of the complex was measured and calcined in hot air furnace Carbolite model at variable temperatures of $500,600,700$ and $800^{\circ} \mathrm{C}$ between $30^{\circ} \mathrm{C}$ to $900^{\circ} \mathrm{C}$ at $10^{\circ} \mathrm{C} \mathrm{min}{ }^{-1}$ for $3 \mathrm{~h}$. These temperatures were chosen because the ligands decompose at temperature above $500^{\circ} \mathrm{C}$. The product was best calcined between $700-800^{\circ} \mathrm{C}$ and purified by washing with $2 \mathrm{M}$ ammonium hydroxide solution to remove phosphate $\left(\mathrm{PO}_{4}\right)^{-2}$ and dried for 2 hours in an oven at $100^{\circ} \mathrm{C}$. The copper oxide was confirmed by XRD powder diffraction method using Rigaku diffractometer Smart lab model, X-ray diffractometer with $\mathrm{Cu} \mathrm{K \alpha}$ radiation $2 \theta$ ranging from $10^{\circ}$ to $90^{\circ}$ at room temperature heating rates of $10^{\circ} \mathrm{C} \mathrm{min}^{-1}$ for 2 hours at wavelength of $1.54 \AA$.

\section{Catalytic performance of the catalyst in the reduction of 4- nitrophenol}

A freshly prepared aqueous $\mathrm{NaBH}_{4}(1 \mathrm{~mL}, 0.2 \mathrm{~mol})$ was mixed with an aqueous solution of 4-NP ( $3 \mathrm{~mL}, 0.01 \mathrm{~mol})$ in a quartz cuvette with $1.0 \mathrm{~cm}$ path length and $4 \mathrm{~mL}$ volume. The solution was prepared using deionized water. The colour of the solution changed immediately to deep-yellow colour upon addition of $\mathrm{NaBH}_{4}$. Then the catalyst (1 mol\%) was added to the mixture, and the initial yellow colour of the solution turned to colourless as the reaction proceeded. The progress of the reduction was evaluated by UV-Vis spectrophotometer in the scanning range between $200 \mathrm{~nm}$ to $500 \mathrm{~nm}$. The absorbance for the 4nitrophenolate ion peak at $\lambda=400 \mathrm{~nm}$ was recorded in every cycling over $2 \mathrm{~min}$ at room temperature. A standard calibration curve was plotted based on six concentrations of 4-NP solutions with $\mathrm{NaBH}_{4}$ ranging from $0.01-0.1 \mathrm{mM}$. The percentage of conversion from 4-NP to 4-AP was determined by calculation from the absorbance data using the following equation:

$$
\text { Percentage conversion }=\frac{\text { Initial Abs - Final Abs }}{\text { Initial Abs }} \times 100 \%
$$

\section{Isolation of the product}

The progress of the conversion reaction was monitored by UV-Vis spectroscopy. When the conversion was completed, the product was isolated by the following procedure. Firstly, the product was diluted with diethyl ether $(30 \mathrm{~mL})$ and separated using liquid-liquid extraction. The extraction steps were repeated three times, and the diethyl ether fractions containing the product (4-AP) were combined and dried using anhydrous sodium sulphate $\left(\mathrm{Na}_{2} \mathrm{SO}_{4}\right)$. Then, diethyl ether was evaporated using a rotary evaporator. Purification of 4-aminophenol by a silica gel column chromatography was done by eluding the product with solvent composed of hexane and ethyl acetate in a ratio of 1:2. Each eluent was loaded on a thin layer chromatography (TLC) plate together with the $30 \mathrm{~mL}$ 4-AP standard. The fraction containing 4-AP were combined, and solvents were evaporated using a rotary evaporator. The product was characterized by NMR and UV-Vis spectroscopy.

\section{Recovery of the catalyst}

The catalyst was recovered by centrifuging the mixture at $4000 \mathrm{rpm}$ for $40 \mathrm{~min}$. After this time, the catalyst was settled at the bottom of the centrifugation tube and recovered by decanting the solution. The recovered catalyst was washed with deionized water twice and dried over silica gel for subsequent experiments.

\section{Optimization of the amount of copper oxide in the reduction of 4-nitrophenol}

The cataytic experiments were repeated three times under the same condition as the model reactions, except that the catalyst amount was varied $(0.5 \mathrm{mg}, 1.0 \mathrm{mg}, 1.5 \mathrm{mg}$ and $2.0 \mathrm{mg})$. Percentage conversion for each catalyst amount was determined from the UV-Vis spectroscopic data.

\section{Recyclability test of copper oxide in the reduction of 4- nitrophenol}

Recycle experiments were performed to test the reusability of the copper oxide catalyst. The recyclability test was performed by carrying out the reaction under the same conditions as the model reaction. After the first run, the catalyst was separated from the reaction mixture by centrifugation. The catalyst was washed twice with deionized water to remove any residue from the catalytic reaction mixture. The separated catalyst was dried in a vacuum desiccator and reused again. In the subsequent run, the same amount of 4-NP and a freshly prepared $\mathrm{NaBH}_{4}$ were used. The percentage conversion of the 4-NP was calculated and compared with the first run.

\section{Reproducibility test of copper oxide in the reduction of 4- nitrophenol}

The catalytic experiments were repeated three times by performing the reaction under the same conditions as the model reaction. For each 
reaction, a fresh catalyst was used to determine the reproducibility of copper oxide.

\section{RESULTS AND DISCUSSION}

\section{Synthesis of 2-acetylpyridine-N(4)-thiosemicarbazone ligand and its copper(I) complex}

The first stage involves the preparation of thiosemicarbazone ligand, from thiosemicarbazide. Thiosemicarbazide was prepared by reacting N(4)-(methoxy-phenyl)isothiocyanate with hydrazine monohydrate at room temperature for 2 hours. The preparation scheme is shown in Fig. 1. The resulting product, N(4)-(methoxyphenyl)-thiosemicarbazide was then reacted with 2-acetylpyridine in ethanol for 4 hours, as decipted in Fig.2 This ligand was characterized using UV-Vis, IR and NMR spectroscopies and characterization data were in good agreement with the literature values [12].

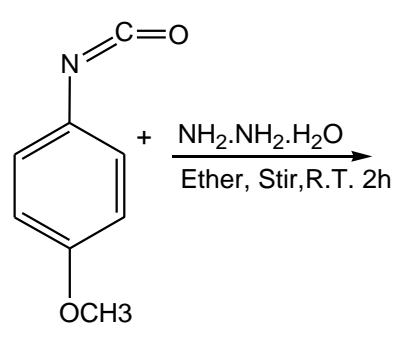<smiles>COc1ccc(NC(N)=S)cc1</smiles>

Fig. 1 Scheme for the preparation of N(4)-methoxyphenyl)thiosemicarbazide<smiles>CCOC(=O)c1cccc(NC(=S)N/N=C(\C)c2ccccn2)c1</smiles>

Fig. 2 Scheme for the preparation of 2-acetylpyridine-N(4)(methoxyphenyl)thiosemicarbazone

Having synthesized the ligand, the next stage involves the synthesis of the copper(I) complex. The copper source for this reaction is tris(triphenylphosphine)copper(I) nitrate, which can be prepared from triphenylphosphine and copper(I) nitrate trihydrate, as shown in Fig. 3. The characterization data of this complex are consistent with the previous reported data [13].

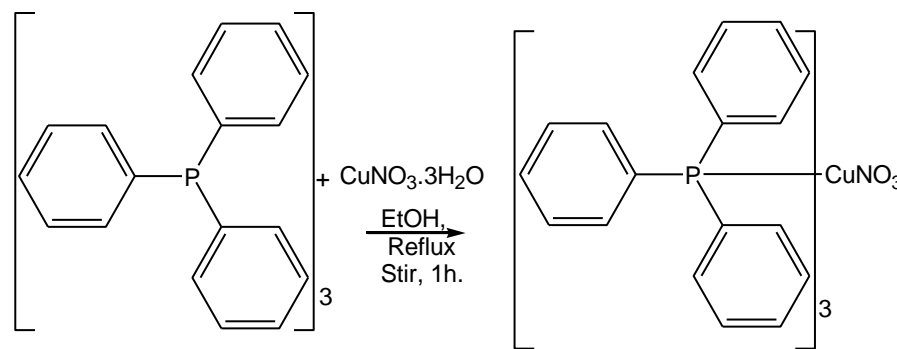

Fig. 3 The preparation scheme of tris-(triphenylphosphine) copper(I) nitrate

The schematic diagram for the preparation of copper(I) complex is displayed in Fig. 4. The copper source, tris-(triphenylphosphine) copper(I) nitrate was reacted with the ligand, 2-acetylpyridine-N(4)(methylphenyl)thiosemicarbazone in dichloromethane and stirred at room temperature for 3 hours. The solvent was removed under vacuum and the product was collected as brown crystals with yield of $78 \%$.<smiles>COc1ccc(NC(=S)N/N=C(\C)c2ccccn2)cc1</smiles>

Fig. 4. The schematic diagram for preparation of 2-acetylpyridine N(4)(methoxyphenyl)thiosemicarbazone copper(I) nitrate

\section{Characterization of thiosemicarbazone ligand and its complex}

Thiosemicarbazone and its copper(I) complex were successfully synthesized and characterized by several characterization techniques, elemental analysis (CHN), UV-Visible, Fourier-transform infrared (FT-IR), nuclear magnetic resonance spectroscopic ( $\left.{ }^{1} \mathrm{H}-\mathrm{NMR}\right)$ techniques. Both the ligand and its complex are yellow and brown in colour respectively, which are similar to the characteristic of other common compounds of thiosemicarbazone [14]. The CHN elemental analyses data of both ligand and complex are consistent with the calculated data, as shown in Table 1.

Table 1. Elemental analysis of $\mathrm{CHN}$ of ligand and its complex

\begin{tabular}{|l|c|c|c|}
\hline Elemental & $\begin{array}{c}\mathrm{C} . \\
\text { Found/Calcd }\end{array}$ & $\begin{array}{c}\mathrm{H} . \\
\text { Found/Calcd }\end{array}$ & $\begin{array}{c}\mathrm{N} . \\
\text { Found/Calcd }\end{array}$ \\
\hline Ligand & $60.23 / 60.00$ & $5.41 / 5.37$ & $18.69 / 18.66$ \\
\hline Complex & $69.06 / 69.01$ & $5.03 / 5.07$ & $5.92 / 5.96$ \\
\hline
\end{tabular}

The electronic absorption spectra of both ligand and its complex were recorded in a solution of chloroform $\left(10^{-3} \mathrm{M}\right)$ in the wavelength range of $200-800 \mathrm{~nm}$. In the spectra of the free ligand, the band at 255 $\mathrm{nm}$ was assigned to $\mathrm{n}-\pi^{*}$ transitions of thioamide, whilst the absorption at $317 \mathrm{~nm}$ corresponds to a $\pi-\pi^{*}$ transition of the pyridine ring and azomethine $[13,15]$. The absoprtion bands of the complex appear at $265 \mathrm{~nm}$ owing to $\mathrm{n}-\pi^{*}$, and the other one at $428 \mathrm{~nm}$ corresponds to $\pi-\pi^{*}$ transitions. By comparing the frequency of free ligands and the corresponding copper(I) complexes, the electronic transitions of $n-\pi^{*}$ are shifted to a higher value due to the formation of the complexes and coordination of the ligand to the copper. This data is consisent with other similar copper complexes [16, 17, 18]. Figure 5 displays the UV-Vis spectra of the ligand and its complex, marked as black and red respectively.

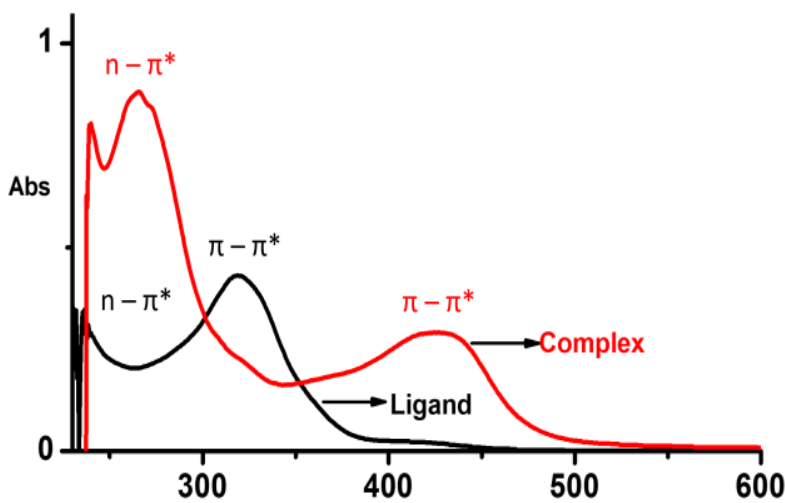

Fig. 5 The UV-Vis spectra of thiosemicarbazone ligand (black) and the copper(I) complex of thiosemicarbazone (red). 
In addition, Figure 6 shows the IR spectra of the ligand and the complex, while the IR frequencies of selected groups in both the ligand and complex are given in Table 2 . The bands observed in the free ligand, at 1610 and $1526 \mathrm{~cm}^{-1}$, correspond to $v(\mathrm{C}=\mathrm{N})$ of pyridine (py) and azomethine (azo). These bands are shifted to 1584 and $1509 \mathrm{~cm}^{-1}$ in the complex, indicating coordination of azomethine and nitrogen to the copper, which is consistent with the other literature data $[19,20]$. Due to the displacement of electron density from $\mathrm{N}$ to $\mathrm{Cu}$ atom, this leads to the weakening of the $v(\mathrm{C}=\mathrm{N})$, as seen in other works [21, 22]. The band observed at $833 \mathrm{~cm}^{-1}$ in the free ligand which attributed to $v(\mathrm{C}=\mathrm{S})$ was not seen in the spectrum of the complex. A new group appeared at lower energy $\left(743 \mathrm{~cm}^{-1}\right)$ indicating coordination of sulphur atom to copper [23]. The appearance of bands at $1446 \mathrm{~cm}^{-1}$ and $694 \mathrm{~cm}^{-}$ ${ }^{1}$ also signify the presence of triphenylphosphine $\left(\mathrm{PPh}_{3}\right)$ in the complex. The absorption band at $1384 \mathrm{~cm}^{-1}$ in the complex indicates the presence of free nitrate, $\mathrm{NO}_{3}$, which in agreement with other published works $[24,25,26]$.

Table 2 Selected IR data of the ligand and copper(I) complex

\begin{tabular}{|l|c|c|c|}
\hline Compd/Freq. & $\begin{array}{c}\text { Pyridine (py) } \\
v(\mathrm{C}=\mathrm{N}) / \mathrm{cm}^{-1}\end{array}$ & $\begin{array}{c}\text { Azomethine } \\
(\mathrm{azo}) \\
v(\mathrm{C}=\mathrm{N}) / \mathrm{cm}^{-1}\end{array}$ & $\begin{array}{c}\text { Thio } \\
v(\mathrm{C}=\mathrm{S}) / \mathrm{cm}^{-1}\end{array}$ \\
\hline Ligand & 1610 & 1526 & 833 \\
\hline Complex & 1584 & 1509 & 743 \\
\hline
\end{tabular}

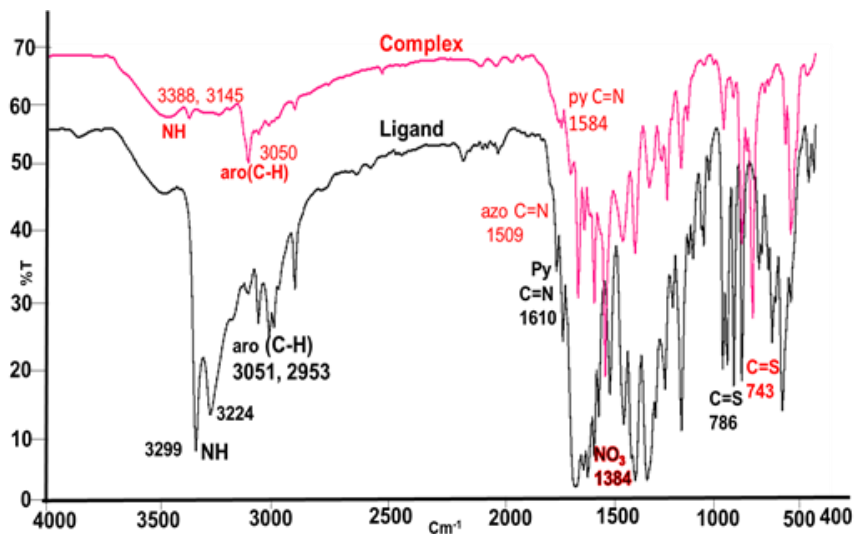

Fig. 6 The IR spectra of thiosemicarbazone ligand (black) and the copper(I) complex of thiosemicarbazone (red).

Meanwhile, Figures 7 and 8 portray the ${ }^{1} \mathrm{H}$-NMR spectra of the ligand and complex respectively, while some selected spectroscopic data are given in Table 3. The resonance of phenyl protons in the free ligand shifted from $\delta_{\mathrm{H}} 9.6$ to $9.2 \mathrm{ppm}$ in the complex, whilst the peak of the imine protons in the ligands moved from $\delta_{\mathrm{H}} 9.9$ to $12.0 \mathrm{ppm}$, indicating the coordination of the ligand to the copper. The downfield shift of the imine protons of the complex compared to the free ligand is attributed to deshielding effect, as the electron density around the imine proton decreases upon coordination of the ligand to copper ion [20,27]. In addition, two sharp singlets appeared at $\delta_{\mathrm{H}} 3.8 \mathrm{ppm}$, and $2.5 \mathrm{ppm}$ are assigned to methoxy $\left(\mathrm{C}-\mathrm{OCH}_{3}\right)$ and methyl $\left(\mathrm{CH}_{3}\right)$ equivalent protons respectively, in both ligand and complex.

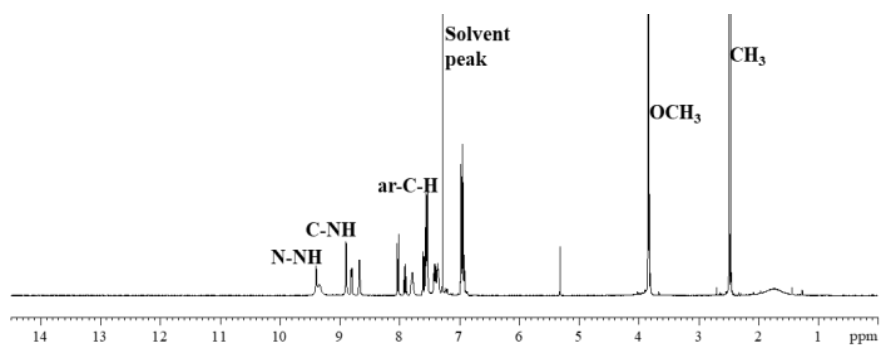

Fig. 7 The ${ }^{1} \mathrm{H}$ NMR spectrum of the ligand.

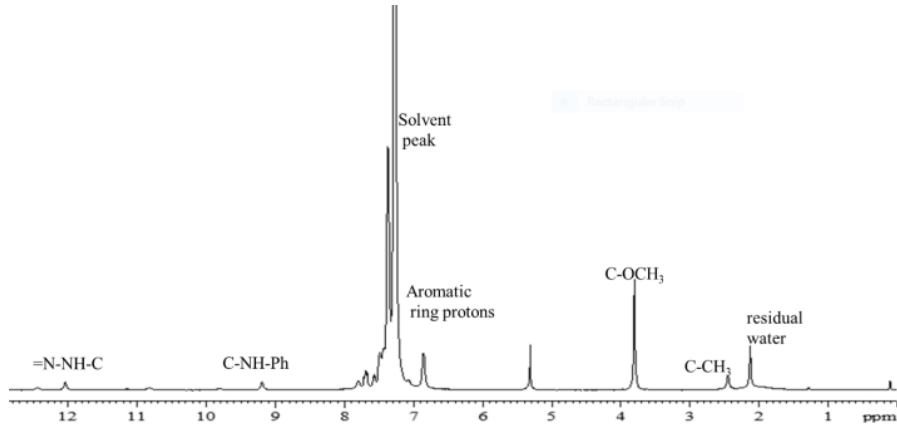

Fig. 8 The ${ }^{1} \mathrm{H}$ NMR spectrum of copper(I) complex.

Table $3{ }^{1} \mathrm{H}-\mathrm{NMR}$ of ligand and its complex.

\begin{tabular}{|l|c|c|c|c|c|}
\hline Compd & $\begin{array}{c}\mathbf{\delta}(\mathbf{N}-\mathbf{N H}- \\
\mathbf{C}) / \mathbf{p p m}\end{array}$ & $\begin{array}{c}\mathbf{\delta}(\mathbf{N H}- \\
\mathbf{A r}) \\
/ \mathbf{p p m}\end{array}$ & $\begin{array}{c}\mathbf{\delta}(\mathbf{A r}-\mathbf{H}) \\
/ \mathbf{p p m}\end{array}$ & $\begin{array}{c}\mathbf{\delta}\left(\mathbf{O C H}_{3}\right) \\
/ \mathbf{p p m}\end{array}$ & $\begin{array}{c}\mathbf{\delta}\left(\mathbf{C H}_{3}\right) \\
/ \mathbf{p p m}\end{array}$ \\
\hline Ligand & 9.9 & 9.6 & $6.8-8.8$ & 3.8 & 2.5 \\
\hline Complex & 12.0 & 9.2 & $6.8-7.8$ & 3.8 & 2.5 \\
\hline
\end{tabular}

\section{Thermal gravimetric analysis}

Prior to the calcination of the complex, thermal gravimetric analysis was conducted to determine the decomposition temperature. $2.0 \mathrm{~g}$ of the complex was measured for the thermographic analysis using 4000 Perkin Elmer model thermographic analyser instrument under a nitrogen atmosphere with a heating rate of $10^{\circ} \mathrm{C} \mathrm{min}{ }^{-1}$ over the temperature range from 100 to $900^{\circ} \mathrm{C}$. Thermal gravimetric analysis (TGA) measures weight/mass change (loss or gain) and the rate of weight change as a function of temperature, time and atmosphere. Measurement is used primarily to determine the thermal composition of materials and to predict their thermal stability. The thermal properties of the ligand and its metal complex were investigated using this method. Figure 9 shows the recorded TGA and differential gravimetric analysis (DTA) curves of ligand (a) and copper(I) complex (b). Copper(I) complex was heated under a nitrogen atmosphere with a heating temperature range of $30-950^{\circ} \mathrm{C}$, at rate of $10^{\circ} \mathrm{C} / \mathrm{min}$. The thermal decomposition of the ligand and its metal complex showed three stages and these were irreversible. The first stage of the TGA degradation was from $70-170^{\circ} \mathrm{C}$, which corresponded to the lost of lattice water with the mass loss of $15.0 \%$, while the second stage occured in the temperature range between $200-300^{\circ} \mathrm{C}$, indicating the removal of triphenylphosphine with mass lost of $65.0 \%$ associated with exothermic peaks at $180^{\circ} \mathrm{C}$ and $310^{\circ} \mathrm{C}$. The final decomposition stage occurred between the temperature range of $340-620^{\circ} \mathrm{C}$, which attributed to the free ligand with weight loss of $15.0 \%$, leaving stable copper oxide as a residue between $640-950^{\circ} \mathrm{C}$, consistent with the previous data [28, 29]. Ning and co-workers studied the thermal stability of a copper dicarboxylate ligand and they observed that the decomposition occurred in three stages. The first stage involved the loss of water from $130-185^{\circ} \mathrm{C}$ (Calc. $18.76 \%$ ). The second weight loss happened in the range of 188 to $600^{\circ} \mathrm{C}$, which was due to the decomposition of an organic ligand (Calc., 59.1\%). The final thermal product after $450{ }^{\circ} \mathrm{C}$ was $\mathrm{CuO}$ particles (Calc., 27.6\%) [30]. Based on this observation, solid state thermal decomposition method provides a simple, efficient and inexpensive way of producing copper oxide.

\section{X-ray diffraction (XRD) of the copper oxide}

Copper oxide obtained from the thermal decomposition of copper(I) complex was confirmed by the characteristic peaks observed in the XRD pattern, as shown in Fig. 10. XRD analysis showed intense peaks at $35.45^{\circ}, 35.55^{\circ}, 38.74^{\circ}, 38.93^{\circ}, 48.74^{\circ}, 51.38^{\circ}, 58.30^{\circ}, 61.56^{\circ}$ and $65.84^{\circ}$, which correspond to (-011), (002), (110), (202), (-202), (202), (202), (113), (-022) and (113) respectively. The observed diffraction reflections were comparable with other literature data [31, 32]. All diffraction peaks could be indexed as the typical monoclinic structure and no extra diffraction peaks of other phases were observed [28, 30]. 


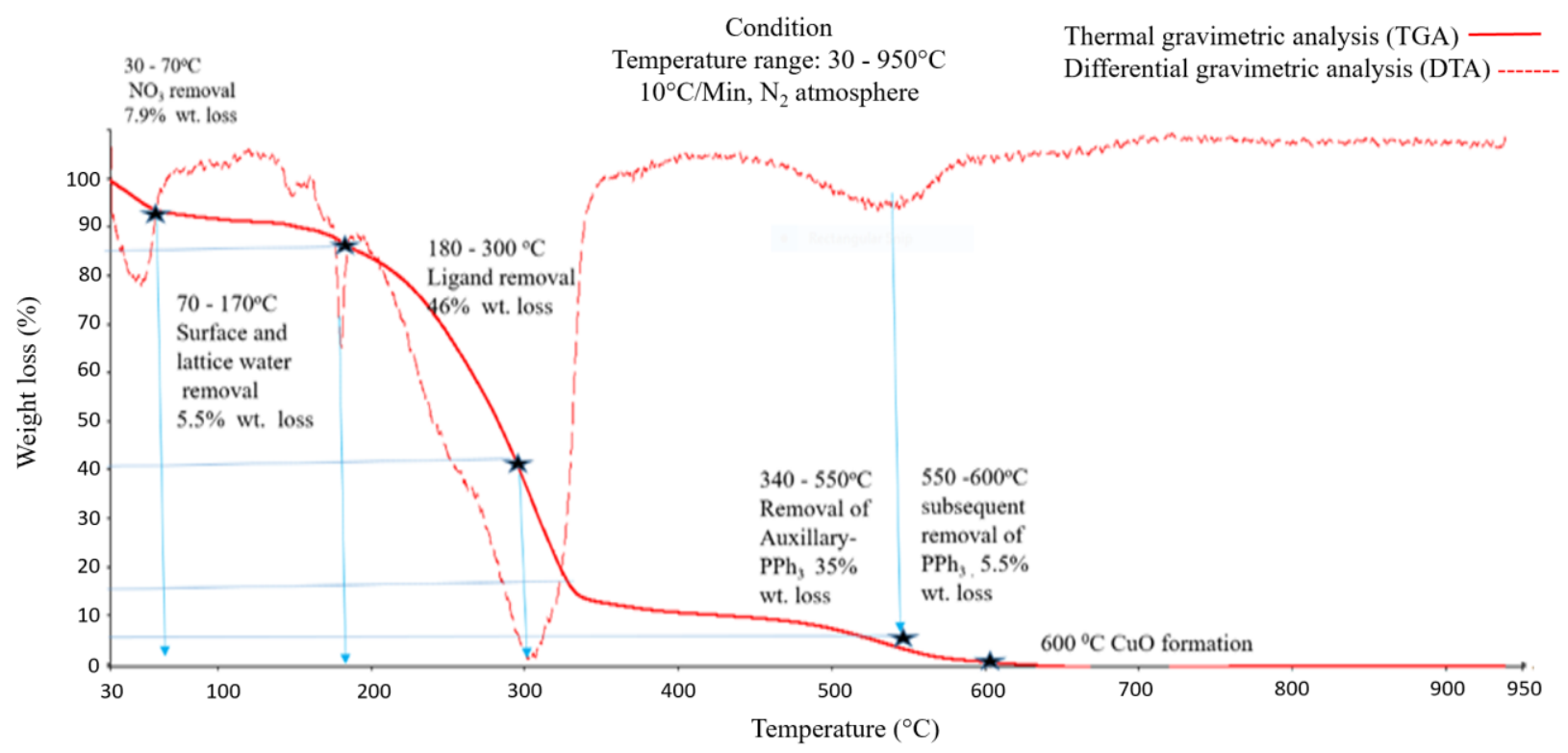

Fig. 9 The TGA analysis of copper(I) complex.

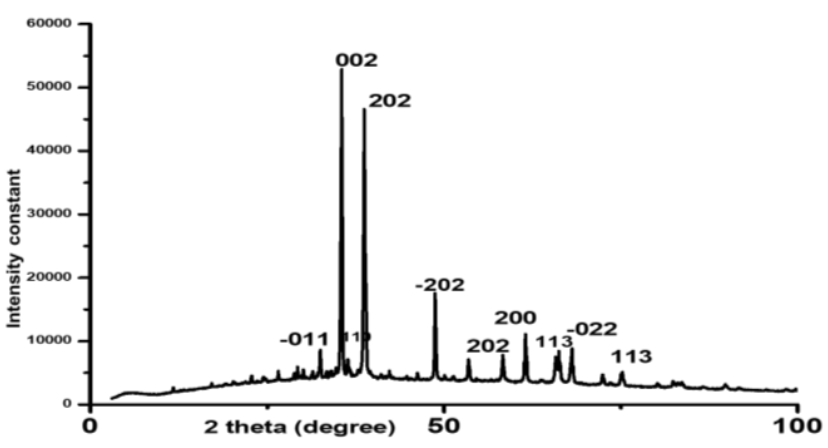

Fig. 10 The XRD pattern of copper oxide.

\section{Catalytic activity of copper-based catalysts in the reduction of 4-nitrophenol}

Reduction of 4-nitrophenol (4-NP) to 4-aminophenol (4-AP) was selected as a model reaction to evaluate the catalytic activity of copperbased catalysts. This reaction provides a straightforward assessment of catalysts using the kinetic parameters extracted from the real-time spectroscopic monitoring of an aqueous solution by using UV-Visible spectrophotometer. In this study, the catalytic activity of copper(I) complex and its oxide were evaluated in the reduction of 4-NP at room temperature, in the presence of $\mathrm{NaBH}_{4}$, as presented in Fig. 11 below. When 4-NP was mixed with $\mathrm{NaBH}_{4}$, the solution became yellowish and has a maximum absorbance at $400 \mathrm{~nm}$ due to the formation of 4nitrophenolate anion. This peaks is very distinctive in the UV-Vis spectrum as shown in Fig. 12. Upon the addition of the catalyst, the peak at $400 \mathrm{~nm}$ was started to decrease whilst a new peak around 300 $\mathrm{nm}$ was appeared at the same time. The new peak at $260 \mathrm{~nm}$ was due to an absorbance of the reaction product, 4-AP. Time was recorded for the complete disappearance of the peak at $400 \mathrm{~nm}$. The time taken for the disappearance of the peak at $400 \mathrm{~nm}$ is proportional to the catalytic performance of the catalyst used.<smiles>O=[N+]([O-])c1ccc(O)cc1</smiles>
$\underset{\mathrm{NaBH}_{4}}{\mathrm{CuO} \text { catalyst }}$

Fig. 11 The schematic diagram for the reduction of 4-nitrophenol to 4aminophenol, catalyzed by copper-based catalyst.

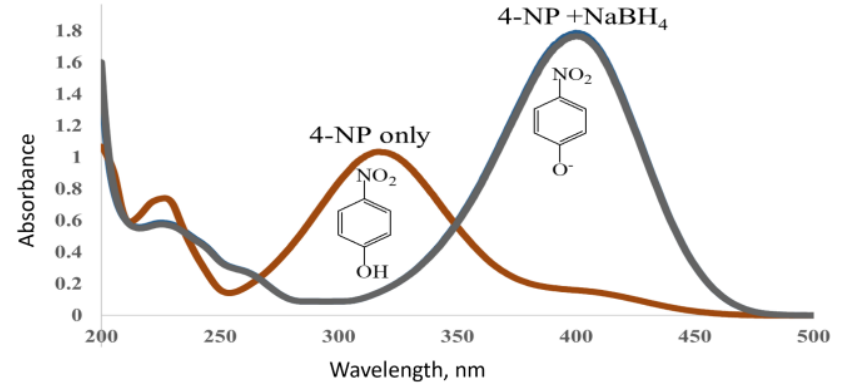

Fig. 12 Monitoring the progress of reaction using UV-Vis spectroscopy.

Fig. 13 shows the reduction of 4-NP by copper(I) complex. Based on this graph, the conversion was measured as $78.2 \%$ over $420 \mathrm{~min}$. The experiment was repeated by using copper oxide as catalyst and the conversion was determined as $98.7 \%$ at 16 minutes (see Fig. 14). Based on these values, it shows that catalytic activity of copper oxide-derived from copper(I) complex was higher than those of the complex.

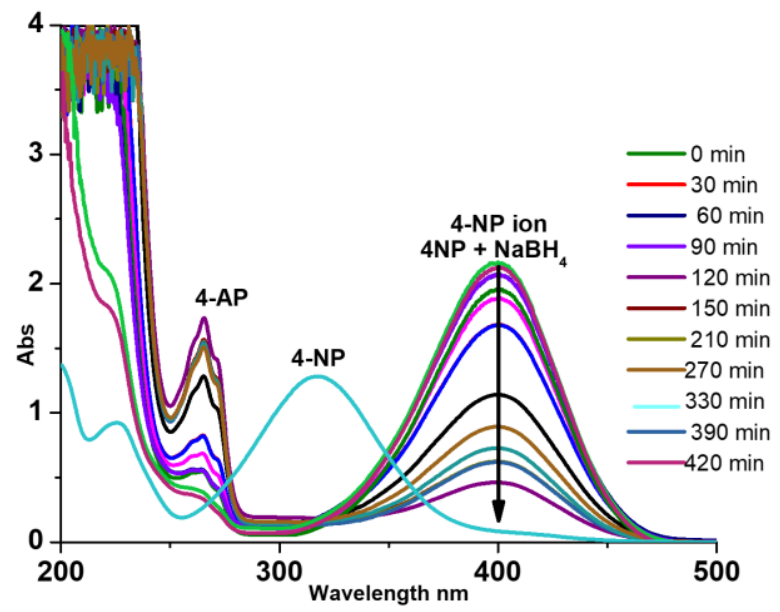

Fig. 13 The UV-Vis spectrum of the reduction of 4-NP with copper(I) complex. 


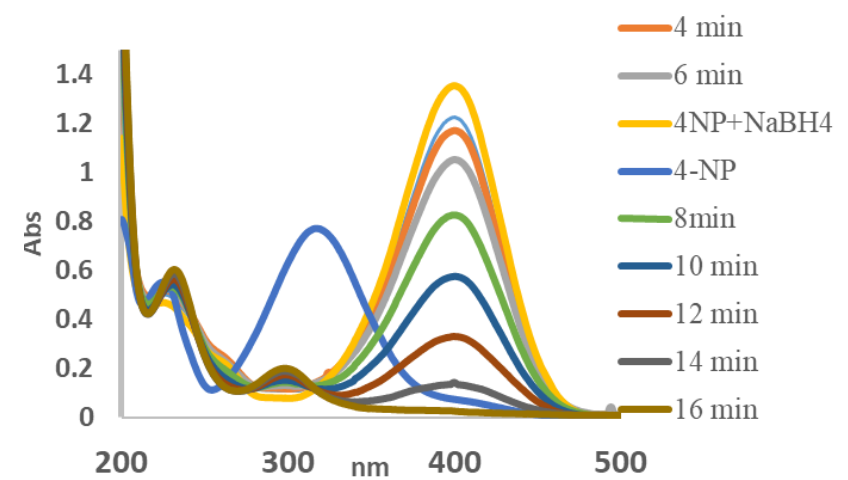

Fig. 14 UV-Vis spectrum of the reduction of 4-NP catalysed by copper oxide.

For quantitative analysis, a calibration curve was constructed with 4NP solution. A linear regression equation of $y=24.357 x+0.025$ with correlation coefficient of 0.997 in the concentration range of $0.01-0.12$ $\mathrm{mM}$ was obtained, as shown in Fig. 15. Based on this equation, the conversion yield of 4-NP to 4-AP was measured to be $98.7 \%$. A reaction rate was measured from the plot between $\ln \left(\mathrm{A}_{t} / \mathrm{A}_{0}\right)$ versus time $(\mathrm{sec})$. Herein, the 4-NP concentrations at time $\mathrm{t}=0$ and time, $\mathrm{t}$ were expressed as $A_{0}$ and $A_{t}$, respectively. It was shown that there was a linear relationship between $\ln (\mathrm{At} / \mathrm{A} 0)$ and time $(\mathrm{sec})$, suggesting that the reaction followed a pseudo-first order kinetics with a rate constant value of $1.7 \times 10^{-3} \mathrm{~s}^{-1}$ (see Fig. 16).

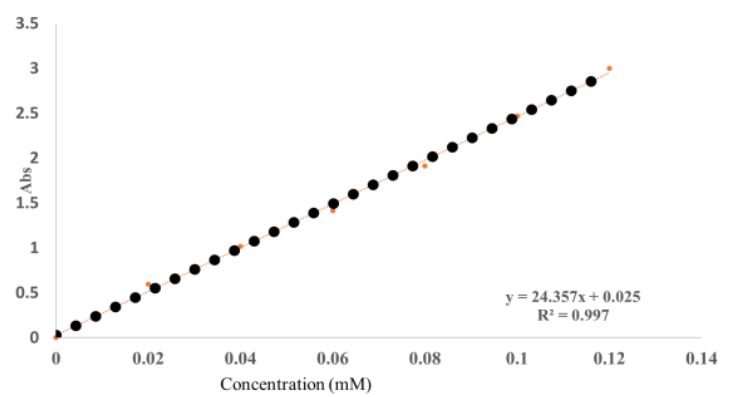

Fig. 15 Calibration curve of 4-NP at different concentrations.

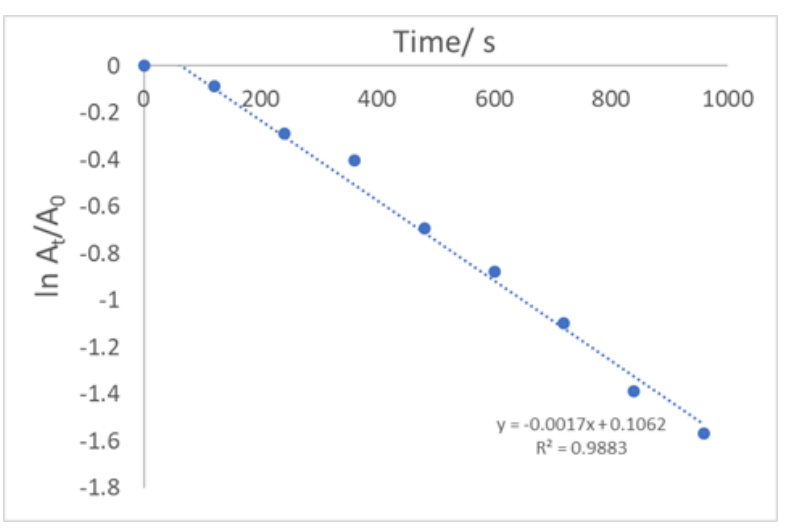

Fig. 16 A graph showing $\ln \left(A_{t} / A_{0}\right)$ versus time (s).

\section{Optimization, recyclability and reproducibility of copper} oxide

Due to the efficiency of copper oxide as a catalyst in the reduction of 4-NP to 4-AP, further investigations were carried out to determine the catalytic properties of copper oxide. In this work, optimization of the catalyst amount of copper oxide was done by varying the amount of catalyst loading in the reduction experiment. For this purpose, different amounts of copper oxide were used in each experiments whilst the other reaction conditions were kept constant. The conversions were measured for each amount and these data are tabulated in Table 4 below. According to the results, the catalytic loading of $1.0 \mathrm{~mol} \%$ was the optimized amount due to its highest conversion, as compared to other catalytic amounts.

Table 4 The optimization copper oxide with different catalyst amount.

\begin{tabular}{|c|c|}
\hline Catalyst amount / mol\% & Conversion $/ \%$ \\
\hline 0.5 & 96.8 \\
\hline 1.0 & 98.7 \\
\hline 1.5 & 95.4 \\
\hline 2.0 & 89.6 \\
\hline
\end{tabular}

The recyclability of the copper oxide for reduction of 4-NP was investigated by employing the used copper oxide as a catalyst in the successive cycles of reaction. The used copper oxide was collected by centrifugation and washed thoroughly with deionized water to remove any residues from previous catalytic reactions, so that it can be reuse again in the next repetitive runs. These recyclability tests were repeated three times, and the results are illustrated in Table 5. Based on the results, copper oxide showed a relatively good catalytic activity even in the forth cycle, with $91.6 \%$ conversion. The slight decrease in the catalytic performance may be due to the loss of catalyst mass during the catalyst recovery process. Nevertheless, this proves tht copper oxide is an efficient catalyst in the reduction of 4-NP and could be reused three times without significant decrease in the catalytic activities.

Table 5 Recyclability test of copper oxide.

\begin{tabular}{|l|c|}
\hline & Conversion $/ \%$ \\
\hline First cycle & 98.7 \\
\hline Second cycle & 96.9 \\
\hline Third cycle & 94.9 \\
\hline Forth cycle & 91.6 \\
\hline
\end{tabular}

In addition, the reproducibility test was also performed to evaluate the consistency and accuracy of the conversions. This is done by repeating the reduction of 4-NP under the same conditions with fresh samples of copper oxide in each run. The conversions for each run were measured and tabulated in Table 6. The results indicate that copper oxide shows a high reproducibilty data with consistent catalytic ativity.

Table 6 Reproducibility test of copper oxide

\begin{tabular}{|l|c|}
\hline & Conversion / \% \\
\hline First, run & 98.7 \\
\hline Second run & 98.4 \\
\hline Third run & 98.8 \\
\hline Forth run & 98.6 \\
\hline
\end{tabular}

\section{Purification and characterization of product}

To determine the successful conversion of 4-NP to 4-AP, the product, 4-AP must be purified and characterized. The product was purified by a silica gel column chromatography and characterized by ${ }^{1} \mathrm{H}$ NMR spectroscopy techniques. Fig. 20 shows the proton NMR spectrum of the product, 4-aminophenol. The appearance of signals at $\delta_{\mathrm{H}} 6.49$ and $4.39 \mathrm{ppm}$ are due to the aromatic proton and amino protons respectively. Meanwhile, the extra two peaks at 3.5 and $2.5 \mathrm{ppm}$ correspond to the solvent and residual water respectively. The proton NMR of the starting material, 4-nitrophenol is shown in Fig. 21 for comparison. The full NMR assignment is illustrated as following and these data are consistent with the standard 4-AP [33].

4-Aminophenol (purified): $1 \mathrm{H} \mathrm{NMR} \mathrm{(400} \mathrm{MHz,} \mathrm{DMSO):} \delta \mathrm{H}=8.36$ (s, 1H), 6.47 (d, J=8.4 Hz, 2H), $6.42(\mathrm{~d}, J=8.4 \mathrm{~Hz}, 2 \mathrm{H}), 4.35$ (s, 2H). 4-Aminophenol (standard): 1H NMR (400 MHz, DMSO): $\delta \mathrm{H}=8.37$ $(\mathrm{s}, 1 \mathrm{H}), 6.50(\mathrm{~d}, J=8.4 \mathrm{~Hz}, 2 \mathrm{H}), 6.44(\mathrm{~d}, J=8.4 \mathrm{~Hz}, 2 \mathrm{H}), 4.39(\mathrm{~s}, 2 \mathrm{H})$. 


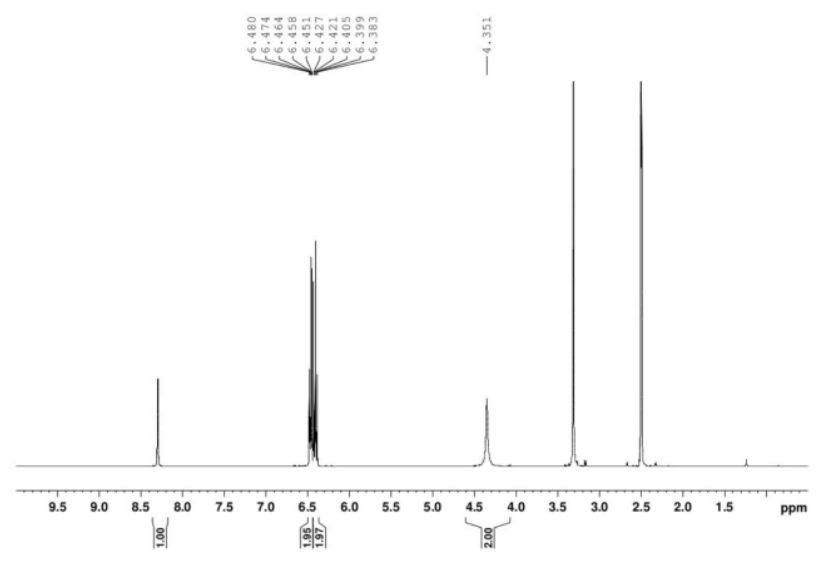

Fig $17{ }^{1} \mathrm{H}-\mathrm{NMR}$ spectrum of the purified 4-aminophenol.

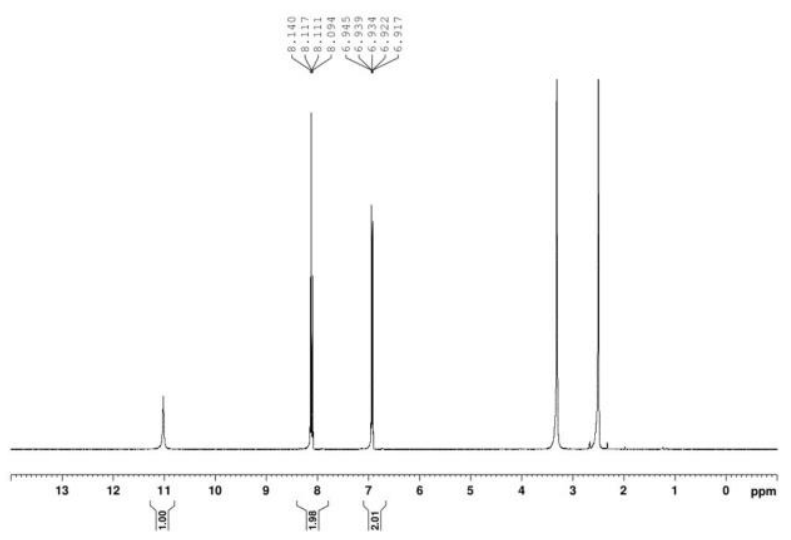

Fig $18{ }^{1} \mathrm{H}-\mathrm{NMR}$ spectrum of 4 -nitrophenol.

\section{CONCLUSION}

A new copper(I) complex of 2-acetylpyridine-N(4)-(methyl phenyl)thiosemicarbazone-tris-(triphenylphosphine) nitrate was successfully synthesized and charazterized by various spectroscopic techniques such as Fourier transform infrared, (FT-IR), UV-visible, (UV), proton nuclear magnetic resonance ( $\left.{ }^{1} \mathrm{H}-\mathrm{NMR}\right)$. Thermal graphic analysis (TGA) and molar conductivity were performed to investigate the properties of the complex. Solid state thermal decomposition technique was successfully employed to convert the complex into copper oxide. This method was simple, efficient, solventless, low cost and environmentally friendly without using any toxic chemicals. The results showed that copper oxide has a higher catalytic activity than the complex, with 97.1 and $78.7 \%$ conversions respectively. Optimization of copper oxide catalyst was performed by varying the catalyst amount, $0.5,1.0,1.5$ and $2.0 \mathrm{~mol} \%$ and the conversions were measured as 96.7, 98.7, 95.4 and $89.6 \%$ respectively. The result indicates that $1.0 \mathrm{mg}$ of catalyst was the optimized catalyst loading for the reduction of 4-nitrophenol to 4-aminophenol. Recyclability and reproducibility tests were performed and the results proved that copper oxide was easily recovered, maintained high and consistent catalytic activities over four cycles without any significant decrease in the conversion of the product.

\section{ACKNOWLEDGEMENT}

The authors would like to thank the Universiti Teknologi Malaysia for the research facilities. O. A. W. H. acknowledge the Federal Government of Nigeria for providing Tetfund assistant through the Federal Polytechnic, Mubi- Adamawa State, to pursue his PhD studies.

\section{REFERENCES}

[1] Li, W., Cui, X., Junge, K., Surkus, A. E., Kreyenschulte, C., Bartling, S., Beller, M. (2019). General and chemoselective copper oxide catalysts for hydrogenation reactions. ACS Catalysis, 9(5), 4302-4307.

[2] Liu, X., Cui, S., Qian, M., Sun, Z., Du, P. (2016). In situ generated highly active copper oxide catalysts for the oxygen evolution reaction at low overpotential in alkaline solutions. Chemical communications, 52(32), 5546-5549.

[3] Bhaumik, A., Haque, A., Karnati, P., Taufique, M. F. N., Patel, R., Ghosh, K. (2014). Copper oxide based nanostructures for improved solar cell efficiency. Thin Solid Films, 572, 126-133.

[4] Grigore, M. E., Biscu, E. R., Holban, A. M., Gestal, M. C., Grumezescu, A. M. (2016). Methods of synthesis, properties and biomedical applications of $\mathrm{CuO}$ nanoparticles. Pharmaceuticals, 9(4), 75.

[5] Velusamy, V., Palanisamy, S., Kokulnathan, T., Chen, S. W., Yang, T. C., Banks, C. E., Pramanik, S. K. (2018). Novel electrochemical synthesis of copper oxide nanoparticles decorated graphene- $\beta$-cyclodextrin composite for trace-level detection of antibiotic drug metronidazole. Journal of Colloid and Interface Science, 530, 37-45.

[6] Kumar, K. Y., Muralidhara, H. B., Nayaka, Y. A. Hanumanthappa, H., Veena, M. S., Kumar, S. K. (2014). Hydrothermal synthesis of hierarchical copper oxide nanoparticles and its potential application as adsorbent for $\mathrm{Pb}$ (II) with high removal capacity. Separation Science and Technology, 49(15), 2389-2399.

[7] Saravanan, S., Sivasankar, T. (2016). Effect of ultrasound power and calcination temperature on the sonochemical synthesis of copper oxide nanoparticles for textile dyes treatment. Environmental Progress \& Sustainable Energy, 35(3), 669-679.

[8] Ameri, B., Davarani, S. S. H., Roshani, R., Moazami, H. R., Tadjarodi, A. (2017). A flexible mechanochemical route for the synthesis of copper oxide nanorods/nanoparticles/nanowires for supercapacitor applications: The effect of morphology on the charge storage ability. Journal of Alloys and Compounds, 695, 114-123.

[9] Sharma, J. K., Akhtar, M. S., Ameen, S., Srivastava, P., Singh, G. (2015). Green synthesis of $\mathrm{CuO}$ nanoparticles with leaf extract of Calotropis gigantea and its dye-sensitized solar cells applications. Journal of Alloys and Compounds, 632, 321-325.

[10] Verma, N., Kumar, N. (2019). Synthesis and biomedical applications of copper oxide nanoparticles: an expanding horizon. ACS Biomaterials Science \& Engineering, 5(3), 11701188.

[11] Monadi, N., Saeednia, S., Iranmanesh, P., Ardakani, M. H., Sinaei, S. (2019). Preparation and characterization of copper oxide nanoparticles through solid state thermal decomposition of an aqua nitrato copper (II) complex with a tridentate schiff-base ligand as a new precursor. Nanoscience \& NanotechnologyAsia, 9(1), 92-100.

[12] Manikandan, R., Viswanathamurthi, P., Velmurugan, K., Nandhakumar, R., Hashimoto, T., Endo, A. (2014). Synthesis, characterization and crystal structure of cobalt (III) complexes containing 2-acetylpyridine thiosemicarbazones: DNA/protein interaction, radical scavenging and cytotoxic activities. Journal of Photochemistry and Photobiology B: Biology, 130, 205-216.

[13] Ramachandran, R., Prakash, G., Vijayan, P., Viswanathamurthi, P., \& Malecki, J. G. (2017). Synthesis of heteroleptic copper (I) complexes with phosphine-functionalized thiosemicarbazones: An efficient catalyst for regioselective $\mathrm{N}$ alkylation reactions. Inorganica Chimica Acta, 464, 88-93.

[14] Omar, S. A., Ravoof, T. B., Tahir, M. I. M., Crouse, K. A. (2014). Synthesis and characterization of mixed-ligand copper (II) saccharinate complexes containing tridentate NNS Schiff bases. $\mathrm{X}$-ray crystallographic analysis of the free ligands and one 
complex. Transition Metal Chemistry, 39(1), 119-126.

[15] Ibrahim, D., Ndahi, N. P., Paul, B. B., Handy, O. W. Synthesis, characterization and antimicrobial activity of 2-Aminopyridinecephalexin schiff base and its Mn (II), Co (II) AND Cu (II) complexes.

[16] Ibrahim, A. B., Farh, M. K., Mayer, P. (2018). Copper complexes of new thiosemicarbazone ligands: Synthesis, structural studies and antimicrobial activity. Inorganic Chemistry Communications, 94, 127-132.

[17] Rogolino, D., Cavazzoni, A., Gatti, A., Tegoni, M., Pelosi, G., Verdolino, V., ...Carcelli, M. (2017). Anti-proliferative effects of copper (II) complexes with hydroxyquinoline-thiosemicarbazone ligands. European journal of medicinal chemistry, 128, 140-153.

[18] Kallus, S., Uhlik, L., van Schoonhoven, S., Pelivan, K., Berger, W., Enyedy, É. A., ... Keppler, B. K. (2019). Synthesis and biological evaluation of biotin-conjugated anticancer thiosemicarbazones and their iron (III) and copper (II) complexes. Journal of inorganic biochemistry, 190, 85-97.

[19] Hakimi, M., Moeini, K., Mardani, Z., \& Takjoo, R. (2014). Synthesis and Spectral Study of a Copper (I) Complex, $[\mathrm{Cu}$ (L)(PPh3) 2], with NS-Donor Ligand. Phosphorus, Sulfur, and Silicon and the Related Elements, 189(5), 596-605.

[20] Jadhav, A. N. \& Chavan, S. S. (2014). Alkynyl functionalized iminopyridine copper(I) phosphine complexes: Synthesis, spectroscopic characterization and photophysical properties. Journal of Luminescence, 148, 296-302.

[21] Chavan, S. S., Sawant, S. K., Pawal, S. B., More, M. S. (2016). Copper (I) complexes of 2-methoxy-(5-trifluoromethyl-phenyl)pyridine-2yl-methylene-amine: Impact of phosphine ancillary ligands on luminescence and catalytic properties of the copper (I) complexes. Polyhedron, 105, 192-199.

[22] Favarin, L. R., Rosa, P. P., Pizzuti, L., Machulek Jr, A., Caires, A. R., Bezerra, L. S., ... \& dos Anjos, A. (2017). Synthesis and structural characterization of new heteroleptic copper (I) complexes based on mixed phosphine/thiocarbamoyl-pyrazoline ligands. Polyhedron, 121, 185-190.

[23] Liu, T., Sun, J., Tai, Y., Qian, H., \&amp; Li, M. (2017). Synthesis, spectroscopic characterization, crystal structure, and biological evaluation of a diorganotin(IV) complex with 2-acetylpyridine N4-cyclohexylthiosemicarbazone. Inorganic and Nano-Metal Chemistry, 47(6), 813-817.

[24] Chen, J. L., Zeng, X. H., Luo, Y. S., Wang, W. M., He, L. H., Liu, S. J., ... \& Wong, W. Y. (2017). Synthesis, structure, and photophysics of copper (i) triphenylphosphine complexes with functionalized 3-(2'-pyrimidinyl)-1, 2, 4-triazole ligands. Dalton Transactions, 46(38), 13077-13087.
[25] Lobana, T. S., Kaushal, M., Virk, R. K., Garcia-Santos, I., \& Jasinski, J. P. (2018). Thiosemicarbazonates of copper: Crystal structures of [(furan-2-acetaldehyde-N-phenylthiosemicarbazonato)][bis (triphenylphosphine)] copper (I) and [bis (furan-2-formaldehyde-N-phenyl-thiosemicarbazonato)] copper (II). Polyhedron, 152, 49-54.

[26] Gunasekaran, N., Bhuvanesh, N. S. P., \& Karvembu, R. (2017). Synthesis, characterization and catalytic oxidation property of copper (I) complexes containing monodentate acylthiourea ligands and triphenylphosphine. Polyhedron, 122, 39-45.

[27] Jamil, M. S. S., Alkaabi, S., \& Brisdon, A. K. (2019). Simple NMR predictors of catalytic hydrogenation activity for $[\mathrm{Rh}(\mathrm{cod})$ $\mathrm{Cl}$ (NHC)] complexes featuring fluorinated NHC ligands. Dalton Transactions, 48(25), 9317-9327.

[28] Li, S. X., Luo, P., \& Jiang, Y. M. (2017). Copper complexes with $4(3 \mathrm{H})$-quinazolinone: Thermal gravimetric analysis and anticancer activity of [Cu (L) $2(\mathrm{H} 2 \mathrm{O}) 2(\mathrm{NO} 3) 2],[\mathrm{Cu}(\mathrm{L}-$ )(NO 3)] n, and [Cu (L) 2 (H 2 O) 2 (Cl) 2]. Russian Journal of Coordination Chemistry, 43(4), 238-243.

[29] Rajalakshmi, S., Vimalraj, S., Saravanan, S., Preeth, D. R., Shairam, M., \& Anuradha, D. (2018). Synthesis and characterization of silibinin/phenanthroline/neocuproine copper (II) complexes for augmenting bone tissue regeneration: an in vitro analysis. JBIC Journal of Biological Inorganic Chemistry, 23(5), 753-762.

[30] Rauf, A., Ye, J., Zhang, S., Shi, L., Akram, M. A., \& Ning, G. (2019). Synthesis, structure and antibacterial activity of a copper (II) coordination polymer based on thiophene-2, 5-dicarboxylate ligand. Polyhedron, 166, 130-136.

[31] Nordin, N. R., \& Shamsuddin, M. (2019). Biosynthesis of copper (II) oxide nanoparticles using Murayya koeniggi aqueous leaf extract and its catalytic activity in 4-nitrophenol reduction. Malaysian Journal of Fundamental and Applied Sciences, 15, 218-224.

[32] Nasrollahzadeh, M., Sajadi, S. M., Rostami-Vartooni, A., Hussin, S. M. (2016). Green synthesis of $\mathrm{CuO}$ nanoparticles using aqueous extract of Thymus vulgaris L. leaves and their catalytic performance for $\mathrm{N}$-arylation of indoles and amines. Journal of colloid and interface science, 466, 113-119.

[33] Sharma, A., Dutta, R. K., Roychowdhury, A., Das, D., Goyal, A., \& Kapoor, A. (2017). Cobalt doped $\mathrm{CuO}$ nanoparticles as a highly efficient heterogeneous catalyst for reduction of 4nitrophenol to 4-aminophenol. Applied Catalysis A: General, 543, 257-265. 